\title{
BMJ Open Intimate partner violence among pregnant women in Rwanda, its associated risk factors and relationship to ANC services attendance: a population-based study
}

\author{
Akashi Andrew Rurangirwa, ${ }^{1,2}$ Ingrid Mogren, ${ }^{3}$ Joseph Ntaganira, ${ }^{1}$ Gunilla Krantz ${ }^{2}$
}

To cite: Rurangirwa AA, Mogren I, Ntaganira J, et al. Intimate partner violence among pregnant women in Rwanda, its associated risk factors and relationship to ANC services attendance: a population-based study. BMJ Open 2017;7:e013155. doi:10.1136/bmjopen-2016013155

- Prepublication history and additional material is available. To view please visit the journal (http://dx.doi.org/ 10.1136/bmjopen-2016013155).

Received 23 June 2016 Revised 18 October 2016 Accepted 16 January 2017

CrossMark

For numbered affiliations see end of article.

\section{Correspondence to}

Dr Akashi Andrew

Rurangirwa; rakashi@nursph. org

\section{ABSTRACT}

Objectives: To investigate the prevalence of four forms of intimate partner violence during pregnancy in Rwandan women, associated sociodemographic and psychosocial factors and relationship to antenatal care service usage.

Design: This was a cross-sectional population-based study conducted in the Northern province of Rwanda and in Kigali city.

Participants and settings: A total of 921 women who gave birth within the past 13 months were included. Villages in the study area were selected using a multistage random sampling technique and community health workers helped in identifying eligible participants. Clinical psychologists, nurses or midwives carried out face-to-face interviews using a structured questionnaire. Bivariable and multivariable logistic regression were used to assess associations.

Results: The prevalence rates of physical, sexual, psychological violence and controlling behaviour during pregnancy were $10.2 \%$ (95\% Cl 8.3 to 12.2$), 9.7 \%$ (95\% Cl 7.8 to 11.6$), 17.0 \%(95 \% \mathrm{Cl} 14.6$ to 19.4$)$ and $20.0 \%$ (95\% Cl 17.4 to 22.6$)$, respectively. Usage of antenatal care services was less common among women who reported controlling behaviour (OR) 1.93 $(95 \% \mathrm{Cl} 1.34$ to 2.79$)$. No statistically significant associations between physical, psychological and sexual violence and antenatal care usage were found. Low socioeconomic status was associated with physical violence exposure (OR) 2.27 (95\% Cl 1.29 to 3.98 ). Also, young age, living in urban areas and poor social support were statistically significant in their associations with violence exposure during pregnancy.

Conclusions: Intimate partner violence inquiry should be included in the standard antenatal care services package and professionals should be trained in giving support, advice and care to those exposed. Genderbased violence is criminalised behaviour in Rwanda; existing policies and laws must be followed and awareness raised in society for preventive purposes.

\section{INTRODUCTION}

Intimate partner violence (IPV) refers to behaviour by an intimate partner or

\section{Strengths and limitations of this study}

- This is the first study in Rwanda that has investigated all forms of intimate partner violence during pregnancy, its associated risk factors and its association with antenatal care service attendance.

- We had a large number of participants and a very low non-response rate.

- We used internationally recognised data collection tools that have been successfully used in similar settings.

- Owing to the sensitive nature of the intimate partner violence, under-reporting of some violent events cannot be ruled out.

- Some data were collected retrospectively from respondents, which can result in recall bias.

ex-partner that causes physical, sexual or psychological harm, including physical aggression, sexual coercion, psychological abuse and controlling behaviours. ${ }^{1}$ IPV exerted towards a pregnant woman may have the most devastating health and social consequences both for the woman herself and for the fetus, ${ }^{2-4}$ and it may determine whether and when a pregnant woman seeks antenatal care services. ${ }^{5-8}$ Physical/sexual abuse may cause a range of health problems such as sexually transmitted infections, chronic pains, fractures as well as stress, anxiety and depression, ${ }^{9}$ and inability to be a good parent after childbirth. ${ }^{6}$ Furthermore, violence during pregnancy has been associated with fetal growth restriction, adverse pregnancy outcomes and childhood growth impairment. ${ }^{10}{ }^{11}$ Depression and stress may subsequently lead to increased levels of stress hormones during pregnancy and reduced placental circulation. ${ }^{10}$ Violence may therefore partly underlie the fetal origins of adult disease theory, that is, fetal programming 
since evidence shows that intrauterine growth restriction is associated with child and adulthood diseases. ${ }^{12}$ The overall prevalence rate of IPV (physical, sexual and/or psychological violence) during pregnancy in the developed world ranges between 10 and 20\%. ${ }^{5}{ }^{13}$ In African countries, the overall prevalence rates of IPV during pregnancy are some of the highest in the world, as high as 25 , 34 and $61 \%$ in Ethiopia, Zimbabwe and the Gambia respectively. ${ }^{3} 6814$ It has been suggested that IPV against women and its effects may be exacerbated in resourcelimited settings, such as Rwanda and many other African countries, due to gender inequality and cultural and economic barriers that restrain women in becoming economically independent. ${ }^{15} 16$ This situation compels women to accept violence exposure from the husband/partner, and the healthcare services are most often inadequate in terms of identifying abused women and offering support. The effects of violence on pregnant women in lowincome countries such as intrauterine growth restriction, miscarriages, preterm birth and fetal death could therefore be related to delayed, incomplete or inadequate antenatal care service attendance, partly as a result of the IPV that pregnant women encounter. ${ }^{8}{ }^{17-19}$

Rwanda is a low-income country in central Africa with $\sim 12$ million inhabitants. ${ }^{20}$ Sixty-four per cent of women and $66 \%$ of men have completed or received some primary school education, whereas $12 \%$ of women and $9 \%$ of men have no formal education. ${ }^{21} 22$ The majority of the low educated or illiterate women live in rural areas, where the fertility rate is higher than the country average of 4.6 children per family. Women are mainly involved in housework and small-scale agricultural activities to contribute to feeding their extended families. ${ }^{22}$ It is a patriarchal society, where IPV may be perceived as a confidential family matter and considered acceptable in order to keep the family together, ${ }^{23}$ although gender-based violence is a punishable offence in the Rwandan penal code. ${ }^{24}$

Studies investigating IPV in Rwanda show that its prevalence ranges between 16 and $50 \%$ and that it occurs in women and men, although women are more frequently and seriously affected. ${ }^{22} 25{ }^{26}$ However, these studies did not give the overall prevalence of the different forms of IPV or did not investigate its status at all during pregnancy.

Therefore, in a population-based cross-sectional study including 921 Rwandan women who delivered $\leq 13$ months ago, the prevalence of IPV during pregnancy, associated risk factors and its relationship with usage of antenatal cares services were investigated. This study forms part of the Maternal Health Research Programme (MaTHeR) undertaken by the University of Rwanda in collaboration with the University of Gothenburg and Umeå University in Sweden.

\section{METHODS}

Study design, study population and sample size

This cross-sectional population-based study was conducted in the Northern Province and in Kigali city, the capital and largest city in Rwanda. Kigali has urban, semiurban and rural areas, whereas the Northern Province is predominantly rural. The target population was women who gave birth within the past 13 months. The sample size was calculated based on the estimated prevalence of hypertensive disorders during pregnancy $(10 \%),{ }^{27} 28$ as hypertension is one of the major factors to be investigated within this research programme and was the least prevalent among study outcomes. The desired level of precision was set at 0.025 and a design effect of 1.5 was used to take care of the multistage nature of the study. Adding $10 \%$ to the sample size to take care of possible non-responses gave a sample size of 912 women. After data collection, extra data had been collected for 10 more women and it was decided to include them in the study; thus, the sample for analysis comprised 922 women.

The selection process was based on the total population of about 2865000 inhabitants from 4791 villages. ${ }^{20}$ In three steps, villages (the smallest administrative entity in Rwanda), households and study participants were randomly selected in the five districts of the Northern Province and in three districts within Kigali City. First, of 4791 villages located in the study area, it was decided to select in total 48 villages (equal to $1 \%$ ). The villages were then randomly selected from the total number of villages in the study area by using Epi-Info random function. Approximately $20 \%$ of the Rwandan population lives in urban areas. ${ }^{22}$ In order to mirror the country's rural-urban divide, $20 \%$ of the villages were selected from urban areas. Second, the number of households from each village was selected based on the total number of households in each selected village (proportionate to size). With the help of the community health workers (CHWs) who keep maternal records, women who gave birth within the past 13 months were identified and finally the women to be interviewed were randomly selected among eligible women in each household, if more than one were present. If an excess number of households with an eligible woman were at hand in a village, lottery decided which ones to include. In case of fewer eligible women in the village than envisaged in the study, the closest village was approached and the same data collection procedures were used to obtain the remaining number of eligible women. Only one woman refused the interview. The overall response rate was $99.9 \%$.

\section{Data collection procedures}

Data collection took place between July and August of 2014. A structured, paper-based interviewer administered questionnaire including sociodemographic and psychosocial characteristics, items related to physical and sexual violence, psychological abuse and controlling behaviour as well as antenatal care (ANC) attendance and procedures, pregnancy and delivery outcomes and health economics issues was developed. The items for investigating violence were selected from the Women's Health and 
Life Experiences Questionnaire, a validated questionnaire developed by the WHO for research on IPV experience. ${ }^{29} 30$ This instrument has been shown to be cross-culturally valid and has previously been successfully used for similar studies in Rwanda. ${ }^{26} 31$

The questionnaire was translated into Kinyarwanda, the Rwandan national language and pretested but no major changes were made apart from a few adjustments in Kinyarwanda wording. Twelve well-trained interviewers, who were clinical psychologists, nurses or midwives, belonging to a pool of interviewers at the School of Public Health, University of Rwanda were selected. Face-to-face interviews were performed and four supervisors (first author and three colleagues) guided the interviewers. If an eligible woman was not present at the time of interview, the team waited for her to come or went back later to do the interview at the earliest possible time. The supervisors ensured that all selected households were contacted and the supervisors reviewed the filled-in questionnaires before the team left the village. The School of Public Health at the University of Rwanda was the lead implementer of the study. Data entry was performed by four skilled personnel selected from a permanent cohort of data entry clerks from the School of Public Health under the supervision of a data entry manager. After the primary data entry, the information from 100 questionnaires, each including the 96 variables used in this study, were re-entered to check the accuracy of the first data entry. In total, five errors were detected, which corresponds to an error rate of $0.05 \%$ (5/9600). The erroneous data were thereafter corrected. All participants included in this study gave birth to a child who was alive at least up to the date of the interview.

\section{Variables}

\section{Antenatal care visits}

The number of ANC visits was dichotomised into poor ANC services usage and adequate ANC services usage and then used as the outcome variable. The former was defined as having made $\leq 2$ visits to ANC clinics during the course of pregnancy irrespective of the timing, whereas the latter was defined as having made $\geq 3$ visits during pregnancy irrespective of the timing.

\section{Intimate partner violence}

$I P V$ was measured as exposure to physical violence (six items), sexual violence (three items) and psychological abuse (four items) and controlling behaviour (7 items). Women were asked to indicate whether they had been exposed to any of the violent acts during pregnancy. In order to assess the seriousness, trend and time frame of violence against women during pregnancy, the women were also asked whether they were exposed to the same acts of violence ever in life, in the year before the current pregnancy and/or after childbirth. Subsequently, summary measures for each of the forms of violence were constructed mirroring the exposure in the time periods 'ever in life', 'in the year before the current pregnancy', 'during pregnancy' (which was our main period of interest) and 'the period after childbirth'. For each of the forms of violence, women who reported any of the violent acts were considered as exposed.

\section{Sociodemographic and psychosocial variables}

Participants' age was categorised into 15-30 years and $31-46$ years age groups. The number of people in the household was described as a three-category variable (1-3 people, 4-6 people and 7 or more people); then a dichotomised variable was created where the first two categories were combined into the reference category and seven or more were considered the exposed. Marital status was dichotomised into married or cohabitating (reference category) and then single, divorced or widowed were brought together in the exposure category. Women's relationship with household head was assessed as being the wife/partner of the household head, or having any other relationship with the household head such as being the daughter, daughter-in-law, being the household head herself, other family relationship and no relationship, further dichotomised into the wife/partner, or any other relationship; the latter was then used as the exposed category. Ever attended school was responded to with yes/no with the latter as the exposure category. Total household monthly income was made into a three-category variable as more than 36000 FRW (US\$60), between 17501 -35 999 FRW (US\$30$60)$ and $<17500$ FRW (US\$30), later dichotomised into $\leq 17500$ FRW and $\geq 17501$ FRW. Social support was defined as having a family member, a relative or a friend who could lend support to the woman if any problem would arise. This item was responded to with yes/no, with the latter as the exposure category. Partner's age was categorised into $\leq 40$ years and $41-70$ years age groups. Then identical techniques were used to categorise partner's level of education and the total household monthly income as described above for participants. A composite variable of assets in the household was used as a proxy for socioeconomic status of the household. Assets in the household included a radio, a television set, a refrigerator, a bicycle, a motorcycle, a car, a mobile phone and a computer. It was later dichotomised into having at least one of the items or having none of the items, constituting the poorest households. All participants included in this study gave birth to a child who was alive at least up to the date of the interview.

\section{Statistical analysis}

The prevalence and frequency of acts of violence exposure were estimated as $\mathrm{n}, \%$ and number of violence incidents in different time periods. McNemar's test was used to assess statistically significant differences in IPV prevalence during different periods. Associations were investigated between different forms of IPV (predictor variable) and poor usage of antenatal care services and further between sociodemographic and psychosocial risk 
factors and different forms of IPV (outcome variable) during pregnancy by use of bivariable and multivariable logistic regression models. Possible confounders were considered based on statistical significance in bivariable analyses and for theoretical reasons due to findings in earlier studies. All models were therefore adjusted for the woman's and the husband's age, number of people in the household, relationship of the woman with the household head, social support, women and husband's education, occupation and family assets. Finally, the Nagelkerke R-Square test was used to assess the fit of the final models. All measures of association are presented as ORs with their 95\% CIs. All analyses were performed using Statistical Package of Social Sciences V.22.0 for Windows (SPSS, Armonk, New York, USA).

\section{Ethical considerations}

Participation was voluntary for all the selected women and no remuneration was given for participating in the study. Before the interview, the interviewer explained in detail the content of the questionnaire, informed the participants on confidentiality of their responses and of their free choice to withdraw from the study at any time during the interview or later. For the protection of the interviewed women in the households and to maintain confidentiality, only one woman in each household was interviewed. The interview was conducted in privacy between the participant and the interviewer. If the interview was to be interrupted by a visitor, the interviewers had been trained either to terminate the interview or to stop asking about violence and to move on to the less sensitive topics such as pregnancy complications until privacy was guaranteed. If it was not possible for the partner/husband to leave the household at that particular time, the woman to be interviewed would be revisited at another time. If an eligible woman was below18 years of age, her parents or guardians' consent was asked for. A written and signed consent was obtained from all participants. To maintain confidentiality, since IPV is a sensitive issue, which might induce strong feelings among the exposed, women were informed that those in need of any kind of assistance could receive it at a nearby health centre or hospital that was informed in advance about the study.

\section{RESULTS}

\section{Sociodemographic and psychosocial data}

Participants were mostly of low socioeconomic status, had not completed primary school and were engaged in non-skilled work. The mean time since childbirth and the time of the interview was 6.7 months $(\mathrm{SD}=3.5)$. The majority were married or cohabiting $(84.1 \%, \mathrm{n}=774)$. Just over $20 \%$ of the participants $(n=186)$ had poor social support. Partners' sociodemographic and psychosocial characteristics showed a similar trend (table 1). Of all participating women, 20.4\% ( $\mathrm{n}=188), 13 \% \quad(\mathrm{n}=120)$ and $20.6 \%(\mathrm{n}=190)$ had ever been subjected to physical,
Table 1 Sociodemographic and psychosocial characteristics of the study population

\begin{tabular}{|c|c|c|}
\hline Variable & $\mathbf{n}$ & Per cent \\
\hline \multicolumn{3}{|l|}{ Age groups (years) } \\
\hline $15-30$ & 632 & 68.8 \\
\hline $31-46$ & 287 & 31.2 \\
\hline \multicolumn{3}{|l|}{ Number of people in the household $=913$} \\
\hline $1-6$ & 748 & 81.6 \\
\hline 7 or more & 169 & 18.4 \\
\hline \multicolumn{3}{|l|}{ Relationship with household head } \\
\hline Any other relationship & 166 & 18.1 \\
\hline Wife/partner & 753 & 81.9 \\
\hline \multicolumn{3}{|l|}{ Marital status } \\
\hline Single, divorced, widowed, separated & 145 & 15.8 \\
\hline Married or cohabitating & 774 & 84.2 \\
\hline \multicolumn{3}{|l|}{ Highest attained level of education } \\
\hline Incomplete primary school & 416 & 50.1 \\
\hline $\begin{array}{l}\text { Complete primary school or vocational } \\
\text { training }\end{array}$ & 219 & 26.4 \\
\hline Secondary school or university & 195 & 23.5 \\
\hline \multicolumn{3}{|l|}{ Occupation } \\
\hline Skilled work, civil servant, student & 119 & 13.1 \\
\hline Non-skilled work & 528 & 58.2 \\
\hline Not employed, other occupation & 260 & 28.7 \\
\hline \multicolumn{3}{|l|}{ Social support } \\
\hline Good & 733 & 79.8 \\
\hline Poor & 186 & 20.2 \\
\hline \multicolumn{3}{|l|}{ Partner/husband age (years) } \\
\hline$\leq 40$ & 667 & 86.1 \\
\hline $41-70$ & 108 & 13.9 \\
\hline \multicolumn{3}{|c|}{ Partner/husband highest level of education } \\
\hline Incomplete primary school & 283 & 42.9 \\
\hline $\begin{array}{l}\text { Complete primary school or vocational } \\
\text { training }\end{array}$ & 248 & 37.6 \\
\hline Secondary school or university & 128 & 19.5 \\
\hline \multicolumn{3}{|l|}{ Partner/husband occupation } \\
\hline Skilled work, civil servant, student & 174 & 22.6 \\
\hline Non-skilled work & 343 & 44.5 \\
\hline Not employed or other occupation & 253 & 32.9 \\
\hline \multicolumn{3}{|l|}{ Total household monthly income 8) } \\
\hline$<17500$ FRW (US\$30) & 258 & 30.0 \\
\hline 17 501-35 999 FRW (US\$30-60) & 240 & 28.0 \\
\hline$\geq 36000$ FRW (US\$60) & 363 & 42.0 \\
\hline \multicolumn{3}{|l|}{ Household assets summary measure } \\
\hline $\begin{array}{l}\text { Improved (having at least one of the } \\
\text { household items) }\end{array}$ & 715 & 78.7 \\
\hline $\begin{array}{l}\text { Poor (having none of the household } \\
\text { items) }\end{array}$ & 194 & 21.3 \\
\hline
\end{tabular}

sexual and psychological violence, respectively (table 2). Data on lifetime prevalence of controlling behaviour was not available.

\section{The prevalence of IPV and controlling behaviour during pregnancy}

Physical partner violence was reported by $10.2 \%$ (95\% CI 8.3 to 12.2), ( $\mathrm{n}=94)$ of all women during pregnancy, psychological abuse by $17.0 \%$ (95\% CI 14.6 to 19.4), 
Table 2 Prevalence of physical, sexual and psychological violence experienced by women earlier in life, in the year before pregnancy and during pregnancy $\mathrm{N}=921$

\begin{tabular}{|c|c|c|c|c|c|c|c|}
\hline \multirow{2}{*}{$\begin{array}{l}\text { Type of violence } \\
\text { Physical violence }(n=896)\end{array}$} & \multirow[t]{2}{*}{$\begin{array}{l}\text { Ever in } \\
\text { life } n(\%)\end{array}$} & \multirow[t]{2}{*}{$\begin{array}{l}\text { Year before } \\
\text { pregnancy } \\
\mathrm{n}(\%)\end{array}$} & \multicolumn{4}{|c|}{$\begin{array}{l}\text { During pregnancy } \\
\text { Number of events }\end{array}$} & \multirow[t]{2}{*}{$\begin{array}{l}\text { After } \\
\text { delivery } \\
\text { n (\%) }\end{array}$} \\
\hline & & & $n(\%)$ & 1 & $2-3$ & $>3$ & \\
\hline Slapped/threw something at you & $161(17.5)$ & $95(10.3)$ & $85(9.2)$ & $50(5.4)$ & $13(1.4)$ & $22(2.4)$ & $97(10.5)$ \\
\hline Pushed/shoved/pulled your hair & $75(8.1)$ & $28(3.0)$ & $38(4.1)$ & $19(2.1)$ & $6(0.7)$ & $13(1.4)$ & $41(4.5)$ \\
\hline Hit that could hurt & $87(9.4)$ & $40(4.3)$ & $42(4.5)$ & $24(2.6)$ & $4(0.4)$ & $14(1.5)$ & $53(5.8)$ \\
\hline Kicked/dragged or beating & $71(7.7)$ & 30 (3.3) & $35(3.8)$ & $17(1.8)$ & $6(0.7)$ & $12(1.3)$ & $41(4.5)$ \\
\hline Choked or burnt you on purpose & $47(5.1)$ & $14(1.5)$ & $21(2.3)$ & $13(1.4)$ & $2(0.2)$ & $6(0.7)$ & $24(2.6)$ \\
\hline $\begin{array}{l}\text { Threatened or used a weapon against } \\
\text { you }\end{array}$ & $54(5.9)$ & $15(1.6)$ & $23(2.4)$ & $13(1.4)$ & $2(0.2)$ & $8(0.9)$ & $25(2.7)$ \\
\hline $\begin{array}{l}\text { Summary measure of physical violence } \\
\text { Psychological abuse }(n=909)\end{array}$ & 4) & )) & 94( & 60 & $17(1.8)$ & $(1.8)$ & 12.1) \\
\hline $\begin{array}{l}\text { Insulted or made you feel bad about } \\
\text { yourself }\end{array}$ & $175(19: 2)$ & 109 (11.8) & 145 (15.7) & $45(4.9)$ & $39(4.2)$ & $61(6.6)$ & $144(15.6)$ \\
\hline $\begin{array}{l}\text { Belittled or humiliated you in front of } \\
\text { others }\end{array}$ & 75 (8.2) & $35(3.8)$ & $67(7.3)$ & $24(2.6)$ & $9(1.0)$ & $34(3.7)$ & $76(8.3)$ \\
\hline $\begin{array}{l}\text { Did things to scare or intimidate you } \\
\text { purposely }\end{array}$ & $60(6.6)$ & $31(3.4)$ & $59(6.4)$ & $24(2.6)$ & $8(0.9)$ & 27 (2.9) & $59(6.4)$ \\
\hline $\begin{array}{l}\text { Threatened to hurt you or someone you } \\
\text { cared about }\end{array}$ & $53(5.8)$ & $28(3.0)$ & $48(5.3)$ & $19(2.1)$ & $6(0.7)$ & $23(2.5)$ & $51(5.5)$ \\
\hline $\begin{array}{l}\text { Summary measure of psychological abuse } \\
\text { Sexual violence }(n=909)\end{array}$ & 190 & 123 & $157(17.0)$ & $64(6.9)$ & $53(5.7)$ & $40(4.4)$ & $160(17.4)$ \\
\hline $\begin{array}{l}\text { Physically forced you to have sexual } \\
\text { intercourse }\end{array}$ & $94(10.2)$ & $66(7.2)$ & 76 (8.3) & $25(2.7)$ & $19(2.1)$ & $32(3.5)$ & $80(8.7)$ \\
\hline $\begin{array}{l}\text { Did you have sexual intercourse you did } \\
\text { not want because you feared what he } \\
\text { might do }\end{array}$ & $89(9.7)$ & $58(6.3)$ & $69(7.4)$ & $24(2.6)$ & $17(1.8)$ & $28(3.0)$ & $78(8.5)$ \\
\hline $\begin{array}{l}\text { Did he force you to do something sexual } \\
\text { that felt degrading or humiliating }\end{array}$ & $16(1.7)$ & $11(1.2)$ & $23(2.5)$ & $14(1.5)$ & $3(0.3)$ & $6(0.7)$ & $24(2.6)$ \\
\hline Summary measure of sexual violence & $120(13.0)$ & $83(9.0)$ & $89(9.7)$ & $34(3.7)$ & $26(2.8)$ & $29(3.1)$ & $97(10.5)$ \\
\hline
\end{tabular}

$(\mathrm{n}=157)$, sexual violence by $9.7 \%$ (95\% CI 7.8 to 11.6$)$, $(\mathrm{n}=89)$ and controlling behaviour by $20.0 \%(95 \%$ CI 17.4 to 22.6), ( $\mathrm{n}=163)$. Except physical violence, all other forms of violence increased during pregnancy as compared to the year before pregnancy but only psychological abuse showed a statistically significant increase from $13.4 \%(\mathrm{n}=123)$ to $17.0 \%(\mathrm{n}=157)$, ( $\mathrm{p}$ value $<0.01)$. A trend was also observed in that the prevalence rates of physical, sexual and psychological violence and controlling behaviour all increased after childbirth as compared to during pregnancy, but these estimates did not reach statistical significance (see online supplementary table S1, tables 2 and 3 and figure 1). Figure 2 shows the overlapping of different forms of IPV during pregnancy. Just over $4 \%$ (95\% CI 2.9 to 5.6), $(\mathrm{n}=40)$ reported all three forms and the most common overlapping was observed between physical and psychological violence, 3.5\% (95\% CI 2.3 to 4.7$),(n=33)$.

\section{Associations between IPV during pregnancy and poor antenatal care usage}

In bivariable and multivariable logistic regression models, no statistically significant associations were observed between physical, sexual or psychological violence during pregnancy and poor usage of ANC services. Multivariable logistic regression models showed that reporting controlling behaviour was almost twofold associated with poor usage of ANC services as compared to not reporting controlling behaviour (OR 1.93 (95\% CI 1.34 to 2.79) (table 4). Further, we investigated possible interactions between physical, sexual and psychological violence with controlling behaviour and usage of ANC services but no significant interactions were present (results not shown).

\section{Associations between sociodemographic and psychosocial} factors and IPV during pregnancy

To investigate the risk factors for physical, sexual, psychological violence and controlling behaviour during pregnancy, bivariable and multivariable logistic regression analyses were performed. Multivariable analyses showed that low socioeconomic status (measured as having none of the assets in the household) was associated with increased exposure to physical violence OR 2.27 (95\% CI 1.29 to 3.98), psychological abuse exposure was associated with having been pregnant more than once, and low socioeconomic status with ORs of 2.11 (95\% CI 1.19 to 3.75 ) and 2.38 (95\% CI 1.47 to 3.86 ), 
Table 3 Partner's controlling behaviour with prevalence, summary measure and severity of control tactics. $\mathrm{N}=921$

\begin{tabular}{|c|c|c|c|c|}
\hline \multirow[b]{2}{*}{ Items } & \multicolumn{2}{|c|}{$\begin{array}{l}\text { During } \\
\text { pregnancy }\end{array}$} & \multicolumn{2}{|c|}{$\begin{array}{l}\text { After } \\
\text { delivery }\end{array}$} \\
\hline & $\mathbf{n}$ & Per cent & $\mathbf{n}$ & Per cent \\
\hline \multicolumn{5}{|c|}{ He tries to keep you from seeing your friends } \\
\hline No & 852 & 93.8 & 841 & 92.2 \\
\hline Yes & 56 & 6.2 & 71 & 7.8 \\
\hline \multicolumn{5}{|c|}{ He tries to restrict contact with your family of birth } \\
\hline No & 882 & 96.6 & 878 & 96.2 \\
\hline Yes & 31 & 3.4 & 35 & 3.8 \\
\hline \multicolumn{5}{|c|}{ He ignores you and treats you indifferently } \\
\hline No & 834 & 92.2 & 826 & 90.5 \\
\hline Yes & 71 & 7.8 & 87 & 9.5 \\
\hline \multicolumn{5}{|c|}{ He gets angry if you speak with another man } \\
\hline No & 776 & 89.4 & 774 & 85.0 \\
\hline Yes & 92 & 10.6 & 137 & 15.0 \\
\hline \multicolumn{5}{|c|}{ He is often suspicious that you were unfaithful } \\
\hline No & 841 & 93.1 & 833 & 91.5 \\
\hline Yes & 62 & 6.9 & 77 & 8.5 \\
\hline \multicolumn{5}{|c|}{$\begin{array}{l}\text { He expects you to ask his permission before seeking } \\
\text { healthcare for yourself }\end{array}$} \\
\hline No & 769 & 86.2 & 759 & 83.4 \\
\hline Yes & 123 & 13.8 & 151 & 16.6 \\
\hline \multicolumn{5}{|c|}{ He controls how you spend your money } \\
\hline No & 822 & 91.7 & 823 & 90.3 \\
\hline Yes & 74 & 8.3 & 88 & 9.7 \\
\hline \multicolumn{5}{|c|}{ Composite variable scores, controlling behaviour } \\
\hline $\begin{array}{l}\text { No controlling } \\
\text { behaviour }(0) \text { points) }\end{array}$ & 651 & 80.0 & 649 & 71.6 \\
\hline $\begin{array}{l}\text { Controlling behaviour } \\
\text { (1-7) points) }\end{array}$ & 163 & 20.0 & 258 & 28.4 \\
\hline \multicolumn{5}{|c|}{ Controlling behaviour scores (0-7) } \\
\hline 0 & 651 & 80.0 & 649 & 71.6 \\
\hline 1 point & 72 & 8.8 & 106 & 11.8 \\
\hline 2 points & 28 & 3.4 & 51 & 5.6 \\
\hline 3 points & 22 & 2.7 & 38 & 4.2 \\
\hline 4 points & 16 & 2.0 & 26 & 2.9 \\
\hline 5 points & 8 & 1.0 & 21 & 2.3 \\
\hline 6 points & 7 & 0.9 & 6 & 0.7 \\
\hline 7 points & 10 & 1.2 & 10 & 1.1 \\
\hline Total & 814 & 100 & 907 & 100 \\
\hline
\end{tabular}

respectively. Young age and poor social support were associated with exposure to sexual violence, OR 1.84 (95\% CI 1.01 to 3.35$)$ and OR 2.92 (95\% CI 1.63 to $5.24)$, respectively. Finally, women from urban areas (Kigali city) and younger women (15-30 years) were at increased exposure to controlling behaviour with ORs of 1.94 (95\% CI 1.33 to 2.81$)$ and 2.17 (95\% CI 1.35 to 3.47 ), respectively (table 5).

In bivariate analyses, partner/husband's level of education was significantly associated with physical and psychological violence exposure but lost its significance in multivariable analyses (not presented in table 5).

\section{DISCUSSION}

This is the first retrospective study in Rwanda that has investigated the prevalence of all forms of IPV, including controlling behaviour against women during pregnancy. The study also investigated the risk factors for IPV and controlling behaviour during pregnancy and whether IPV exposure would influence usage of ANC services.

Analysing each form of IPV separately, the prevalence of physical violence during pregnancy was $10.2 \%$, which is consistent with $7-12 \%$ found in a similar study in Tanzania. ${ }^{4}$ Prevalence rates for sexual and psychological violence in our study were also similar to the previously reported findings in the region. ${ }^{32}$ However, a crosssectional study among pregnant women in Tanzania gave the prevalence rates of $18 \%$ and $20 \%$ for sexual and physical violence, respectively. ${ }^{33}$ Also, a communitybased cross-sectional study among 282 married pregnant women in Ethiopia reported even higher prevalence rates for all forms of IPV. ${ }^{34}$ The differences in results could be explained by true prevalence differences but also could be due to differences in social beliefs on what constitutes IPV, tools and scales that were used for data collection and analyses and sample size.

There are insufficient data on the prevalence of spouse controlling behaviour during pregnancy. The prevalence of $20 \%$ in our study is lower than the $33.1 \%$ and $42 \%$ reported in Malawi and Nigeria, respectively, ${ }^{35}$ but these studies investigate the partner's controlling behaviour before pregnancy, which might have led to higher rates, as pregnancy may be protective against some forms of violence exposure. However, the lower prevalence rates of controlling behaviour may also be a result of changing perceptions about the role of women in Rwandan society as a result of government's efforts to use gender equality as one of the means to achieve social and economic development by empowering women. Gender equality policies have been institutionalised and there is a female majority parliament.

Results in this study indicate that physical violence decreased slightly during pregnancy, whereas both sexual violence and psychological abuse increased, but a statistically significant change was observed for psychological abuse only. Studies evaluating whether physical violence, sexual violence or psychological abuse increases or decreases during pregnancy have shown mixed results. ${ }^{32} 37$ This could be expected considering the different definitions of IPV that have been used and due to real differences in results. However, our results are consistent with other studies, which show that being pregnant is not necessarily protective against IPV and that physical violence may slightly decrease compared to other forms of IPV probably because of the partner's fear of hurting the unborn baby or due to the cultural unacceptability of hurting a pregnant woman. ${ }^{8} 38$ The reasons as to why psychological abuse increased significantly during pregnancy in our study are not clear but a similar finding is presented from Zimbabwe. ${ }^{3}$ A suggested explanation is that women who have mistimed the pregnancy or if the pregnancy is unwanted endure significantly higher levels of psychological abuse from their partners, who blame them for getting pregnant. ${ }^{39}$ 
Figure 1 Prevalence rates of different forms of IPV at different life phases. $\mathrm{N}=921$. IPV, intimate partner violence.

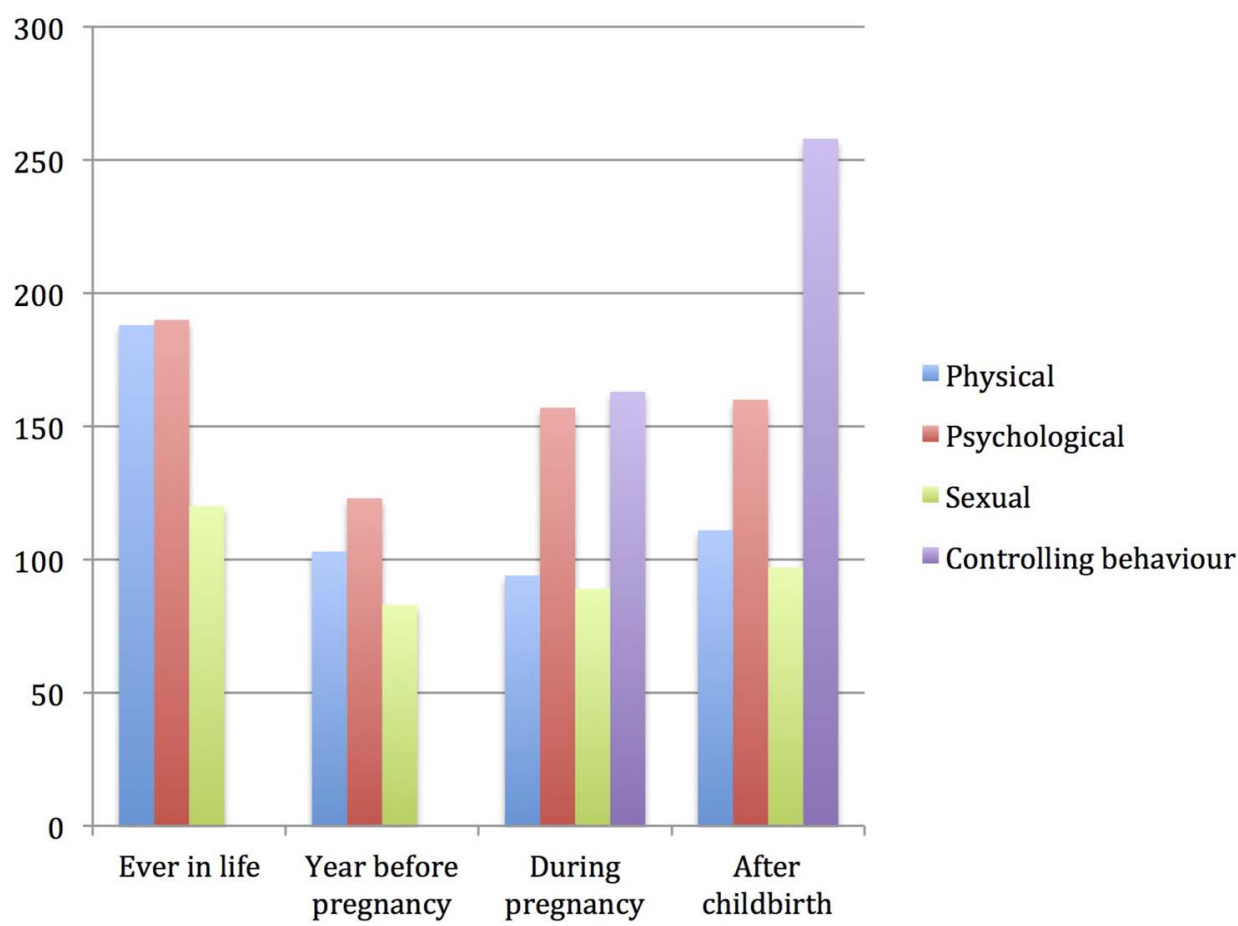

This could be a plausible explanation among our participants who were mainly low educated and living in rural areas where knowledge about contraceptive methods may be an issue and women are less likely to use any form of family planning methods for convenient timing of conception. As a result, it is not surprising that the most common overlapping types of violence during pregnancy were psychological and physical violence.

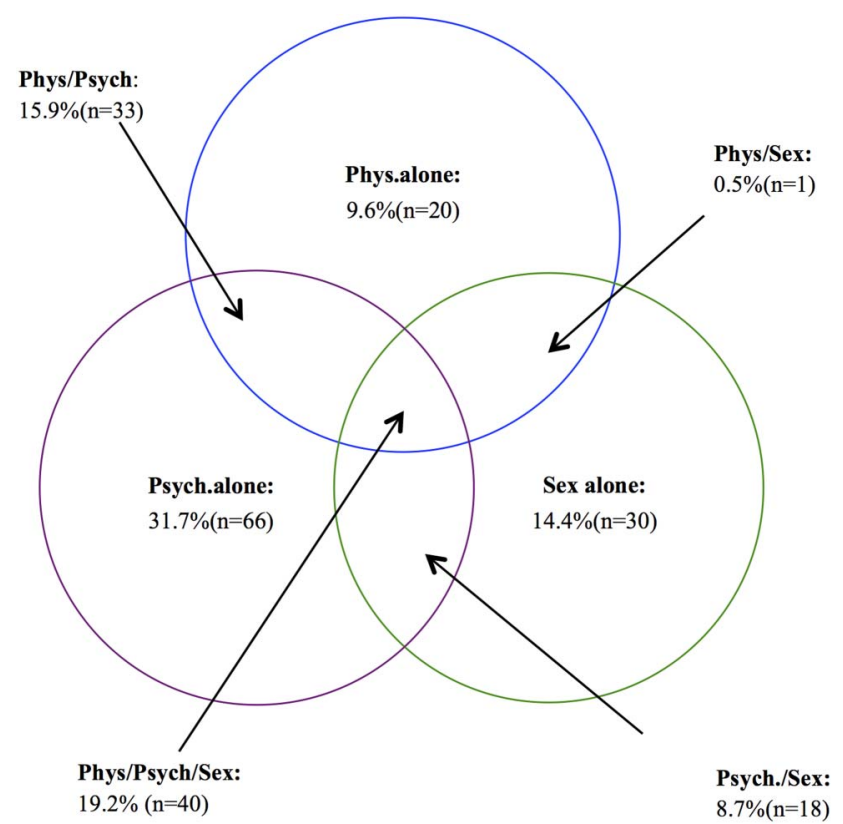

Figure 2 Prevalence rates of overlapping forms of IPV perpetrated against women during pregnancy. $N=208$. IPV, intimate partner violence; Phys: physical violence, Psych: psychological violence, Sex: sexual Violence.
Comparable overlap has been reported in a study from Tanzania. ${ }^{40}$

We have observed that husband/partner's controlling behaviour was associated with poor ANC service attendance, which is in line with a few related findings on this topic in Africa. ${ }^{41}$ However, the lack of associations of all forms of IPV with poor ANC services usage in this study seems counterintuitive. Although studies investigating the direct effect of single forms of IPV exposure on pregnant women's ANC services attendance are scarce, there are a few related ones from sub-Saharan Africa which suggest that IPV exposure may be a risk factor for poor ANC services attendance. ${ }^{184142}$ One of the reasons suggested is lack of sufficient information about ANC services, and partners who directly or indirectly through threats or actual violence stop them from going to ANC clinics. ${ }^{42} 43$ This may not be true in Rwandan settings where there is a highly successful sensitisation and education effort by CHWs to support the community on health-related issues such as ANC services attendance. ${ }^{44}$ Each village of 100-150 households in Rwanda has about four CHWs for this purpose. ${ }^{45}$ CHWs further encourage families to immunise their children, and to inform about various health matters, such as nutrition and malaria prevention issues. However, lack of associations may also be related to disguising intentions; owing to cultural norms prevailing in Rwanda and stigma associated with violence in the community, ${ }^{46}$ abused pregnant women may conceal that they are being abused by attending ANC clinics in order to protect their status and family image in the community. Furthermore, local evidence shows that men are ashamed of the violence they perpetrate against women, ${ }^{23}$ because of its social unacceptability and possible reprimand from authorities 
Table 4 Associations between different forms of violence during pregnancy and poor usage of antenatal care services

Poor usage of antenatal care services

\begin{tabular}{|c|c|c|c|c|}
\hline \multirow[b]{2}{*}{ Type of violence } & \multicolumn{4}{|c|}{ Poor usage of antenatal care services } \\
\hline & $\mathbf{n}$ & (\%) & $\begin{array}{l}\text { Crude OR } \\
(95 \% \mathrm{Cl})\end{array}$ & $\begin{array}{l}\text { Adjusted OR } \\
(95 \% \mathrm{Cl})\end{array}$ \\
\hline \multicolumn{5}{|l|}{ Physical violence } \\
\hline No & 113 & $113(13.7)$ & & \\
\hline Yes & 9 & $9(9.7)$ & 0.67 (0.33 to 1.38$)$ & 0.73 (0.35 to 1.52$)$ \\
\hline \multicolumn{5}{|c|}{ Psychological violence } \\
\hline No & 102 & $102(13.4)$ & 1 & \\
\hline Yes & 20 & $20(12.8)$ & 0.95 (0.57 to 1.59$)$ & 0.93 (0.54 to 1.58$)$ \\
\hline \multicolumn{5}{|l|}{ Sexual violence } \\
\hline No & 111 & $111(13.3)$ & 1 & \\
\hline Yes & 11 & $11(12.5)$ & $0.93(0.48$ to 1.80$)$ & 0.82 (0.41 to 1.63$)$ \\
\hline \multicolumn{5}{|c|}{ Controlling behaviour } \\
\hline No & 73 & $73(10.8)$ & 1 & 1 \\
\hline Yes & 30 & $30(19.1)$ & 1.79 (1.12 to 2.85$)$ & $1.93(1.34$ to 2.79$)$ \\
\hline
\end{tabular}

Bold denotes statistical significance.

$\mathrm{N}=921$.

*Values are controlled for age, women and husband's education, occupation, number of people in the household, relationship with household head, social support and assets in the household.

and in order to hide it, they may encourage their pregnant wives to attend ANC services so that neighbours, CHWs and local administrative authorities do not discover that their wives are being abused. This is supported by results in this study showing that controlling behaviour, which may not be considered as violence, is associated with poor ANC services usage. We will further investigate this rather unexpected finding that physical, sexual or psychological violence does not influence ANC attendance by use of qualitative data.

Results in our study show that low social economic status was associated with both physical and psychological violence during pregnancy. This is in accordance with other findings. ${ }^{47-49}$ Lower household income may be a result of lack of employment, which leads to poverty in the household that can provoke conflicts. ${ }^{23}$ Lower social economic status and lower gender equality awareness may largely explain the higher prevalence rates of IPV that have been observed in low-income countries such as Rwanda as compared to high-income countries. The finding that poor social support and young age are associated with sexual violence during pregnancy is consistent with the findings in other studies. ${ }^{50}$ Abusive and/or controlling partners often aim to isolate the victims from family, friends and social networks, which means lack of intimate forums in which pregnant women can discuss such a sensitive topic as physical/sexual violence during pregnancy in a traditional society as Rwanda. Similarly, young women are more likely to be economically dependent and may not attempt to resist sexual violence because of the fear that their husbands may walk out on them. Consequently, pregnant women may treat the situation as normal and make no attempts to rectify it. The finding that women expecting their first-born were at lower exposure of psychological abuse is not surprising and similar findings have been reported in other studies. ${ }^{32} 47$ The first child is generally a source of happiness and warmth between the couple, whereas having delivered two or more times might present more economic challenges and dependence, which can initiate or increase violence.

We have found that a woman's young age and living in urban areas are risk factors for husband/partner controlling behaviour during pregnancy, which is comparable to previous findings in the region and elsewhere. $^{32} 3652$ In a slowly but gradually changing Rwandan society, young women are more likely to have more social networks and outgoing activities, which may provoke partners with a tendency towards being controlling. Women living in and around Kigali are relatively more educated and/or are more likely to have paid employment than the common and traditional occupation of subsistence farming. As women start to oppose traditional gender role expectations and, to a growing extent, assume non-traditional roles, violence against them has been shown to increase. ${ }^{53}$

\section{Methodological considerations}

The strength of this study is the large sample size, the low non-response rate and the use of internationally recognised tools for all forms of IPV assessment including controlling behaviour. Owing to cultural beliefs and the sensitive nature of IPV, there was a possibility of under-reporting of violent events and information on some variables was missing, which may have resulted in less precise analyses. Nevertheless, data collection was conducted with utmost care, by a team of trained and experienced medical personnel including clinical psychologists, who were able to establish a favourable environment for discussion with participating women. These were of the same sex and of similar age as the participants, which has been shown to improve the accuracy of 
Table 5 Associations between sociodemographic and psychosocial factors and women's exposure to different forms of IPV during pregnancy

\begin{tabular}{|c|c|c|c|c|c|c|c|c|}
\hline Variable & $\begin{array}{l}\text { Physical vic } \\
\mathrm{n}(\%) \text { with } \\
\text { phys. } \\
\text { violence }\end{array}$ & OR $(95 \% \mathrm{Cl})$ & $\begin{array}{l}\text { Psycholog } \\
\text { n (\%) with } \\
\text { psycho. } \\
\text { violence }\end{array}$ & OR $(95 \% \mathrm{Cl})$ & $\begin{array}{l}\text { Sexual viole } \\
\mathrm{n}(\%) \text { with } \\
\text { sexual } \\
\text { violence }\end{array}$ & OR (95\% Cl) & $\begin{array}{l}\text { Controlling } \\
\mathbf{n}(\%) \text { with } \\
\text { cont. } \\
\text { behaviour }\end{array}$ & OR (95\% Cl) \\
\hline \multicolumn{9}{|l|}{ Province } \\
\hline Northern Province & $54(8.8)$ & 1 & $99(16)$ & 1 & $47(7.6)$ & 1 & $89(16.0)$ & 1 \\
\hline Kigali city & $40(8.8)$ & 1.19 (0.68 to 2.06$)$ & $58(19)$ & 1.00 (0.63 to 1.58$)$ & $42(13.8)$ & 1.26 (0.69 to 2.26$)$ & 74 (28.9) & 1.94 (1.33 to 2.81$)$ \\
\hline \multicolumn{9}{|l|}{ Age groups (years) } \\
\hline $15-30$ & $66(10.4)$ & 1 & $108(17.1)$ & 1 & $57(9.0)$ & 1 & $37(14.3)$ & 1 \\
\hline $31-46$ & $28(9.8)$ & 0.99 (0.65 to 1.74$)$ & $49(17.1)$ & 1.44 (0.71 to 1.83$)$ & 32 (11.1) & 1.84 (1.01 to 3.35$)$ & $126(22.8)$ & 2.17 (1.35 to 3.47$)$ \\
\hline \multicolumn{9}{|l|}{ Pregnancies before index child } \\
\hline 0 & $23(8.0)$ & 1 & 35 (12.2) & 1 & $27(9.4)$ & 1 & $50(19.7)$ & 1 \\
\hline$\geq 1$ & $70(11.6)$ & $1.62(0.83$ to 3.18$)$ & $120(20.0)$ & 2.11 (1.19 to 3.75$)$ & 59 (9.89) & 1.04 (0.51 to 2.18$)$ & $108(20.4)$ & 1.41 (0.85 to 2.32$)$ \\
\hline \multicolumn{9}{|l|}{ Relation with household head } \\
\hline Wife/partner & $82(10.2)$ & 1 & $133(17.7)$ & 1 & $71(9.4)$ & 1 & $119(17.9)$ & 1 \\
\hline Any other relationship & $12(7.2)$ & $0.57(0.30$ to 1.15$)$ & $24(14.4)$ & 0.95 (0.33 to 2.74$)$ & $18(10.8)$ & 1.03 (0.62 to 1.97$)$ & $44(29.7)$ & 2.40 (0.94 to 6.09$)$ \\
\hline \multicolumn{9}{|l|}{ Social support } \\
\hline Good & $70(9.5)$ & 1 & $115(15.7)$ & 1 & $56(7.6)$ & 1 & $124(18.8)$ & 1 \\
\hline Poor & 24 (12.9) & 1.23 (0.66 to 2.27$)$ & $42(22.6)$ & $0.86(0.51$ to 1.44$)$ & $33(17.7)$ & 2.92 (1.63 to 5.24$)$ & $38(25.3)$ & 1.33 (0.76 to 2.27$)$ \\
\hline \multicolumn{9}{|l|}{ Household assets summary measure } \\
\hline Improved ( $\geq 1$ item) & $60(8.4)$ & 1 & $106(14.8)$ & 1 & $65(9.1)$ & 1 & $130(20.7)$ & 1 \\
\hline Poor (none of the items) & $31(16.0)$ & 2.27 (1.29 to 3.98$)$ & $48(24.7)$ & 2.38 (1.47 to 3.86$)$ & $22(11.3)$ & 1.40 (0.72 to 2.72$)$ & $32(18.4)$ & $0.90(0.52$ to 1.55$)$ \\
\hline \multicolumn{9}{|c|}{ Partner/husband's level of Education } \\
\hline Secondary school or university & $8(6.3)$ & 1 & $13(10.2)$ & 1 & $10(7.8)$ & 1 & $20(17.9)$ & 1 \\
\hline Complete primary school or VT & $24(9.7)$ & $0.71(0.40$ to 1.23$)$ & $45(18.1)$ & 1.30 (0.66 to 2.56$)$ & $21(8.5)$ & $1.13(0.49$ to 2.75$)$ & $46(20.2)$ & $0.88(0.45$ to 1.72$)$ \\
\hline Incomplete primary school & $38(13.4)$ & $0.63(0.27$ to 1.44$)$ & $52(18.4)$ & 1.33 (0.67 to 2.65$)$ & $30(10.6)$ & 0.88 (0.38 to 2.05$)$ & $39(15.9$ & 1.19 (0.63 to 2.27$)$ \\
\hline \multicolumn{9}{|l|}{ Partner/husband's age (years) } \\
\hline$\leq 40$ & $79(11.8)$ & 1 & $118(17.7)$ & & $63(9.4)$ & 1 & $114(19.4)$ & 1 \\
\hline $41-70$ & $6(5.6)$ & 0.38 (0.14 to 1.04$)$ & $18(16.7)$ & 0.50 (0.23 to 1.07$)$ & $12(11.1)$ & 0.73 (0.31 to 1.74$)$ & $11(11.7)$ & $0.53(0.25$ to 1.15$)$ \\
\hline
\end{tabular}

Bold denotes statistical significance.

Adjusted ORs with their $95 \%$ Cls. N=921.

*Values are from the logistic regression models containing all the variables in the table.

cont, controlling; phys, physical; psycho, psychological; VT, vocational training. 
the reporting in interviews. ${ }^{54}$ The design of our study limits the ability to draw any causal inferences and data from women experiencing IPV whose pregnancies were terminated earlier for whatever reason were not available. Finally, the data were collected retrospectively from respondents who gave birth between 1 and 13 months before the interview with a mean time of 6.7 months, which may have resulted in recall bias. However, the short recall period meant that this was most likely a minor problem. We believe that the findings in this study are generalisable to the entire country, as living circumstances are quite similar in the rest of the provinces in the country.

\section{Conclusion}

This study has demonstrated that all forms of IPV including controlling behaviour against pregnant women in Rwanda are frequent. We recommend that all forms of IPV are included in the standard health assessment package of ANC services and health service providers should regularly be trained and made aware of IPV against pregnant women attending ANC services. Policies aiming at increasing ANC services attendance should be reinforced and CHWs have to be empowered and given sufficient support as they have an important task in raising awareness on the dangers of IPV including controlling behaviour. Existing laws and policy on gender-based violence, which criminalise such behaviour, should be followed in that perpetrators should be convicted in serious cases. Primary prevention is about alerting the media, institutions, organisations, communities and families on the subject, to create an open debate on the subject in society. Finally, more research is needed to determine the effects of IPV during pregnancy on pregnancy outcomes, women's postpartum well-being and the newborn's early childhood, adolescence and adult life.

\section{Author affiliations \\ ${ }^{1}$ Department of Epidemiology and Biostatistics, School of Public Health, University of Rwanda, Rwanda \\ ${ }^{2}$ Section of Epidemiology and Social Medicine (EPSO), Department of Public Health and Community Medicine, The Sahlgrenska Academy at University Gothenburg, Sweden \\ ${ }^{3}$ Department of Clinical Sciences, Obstetrics and Gynecology, Umeå University, Sweden}

Acknowledgements The authors gratefully acknowledge the contribution of all participating women who welcomed us into their homes and gave their valuable time to answer our questions and share their maternal health experience with us. The authors are also grateful to the Section for Epidemiology and Social Medicine (EPSO), at the University of Gothenburg and the School of Public Health, College of Medicine and Health Sciences, University of Rwanda for all the support they provided.

Contributors GK designed the study. GK, IM, AAR and JN developed the study questionnaire. AAR developed the study methodology, coordinated and participated in piloting and data collection activities and carried out all statistical analyses with assistance from GK. The manuscript was drafted and written by AAR with contributions from GK, IM and JN. JN also participated in data collection activities.
Funding This study forms part of the Maternal Health Research Programme (MaTHeR) undertaken by the University of Rwanda in collaboration with the University of Gothenburg and Umeå University in Sweden. The Study was made possible by financial support from The Swedish International Development Cooperation Agency (SIDA).

Competing interests None declared.

Ethics approval Institutional Review Board of the College of Medicine and Health Sciences, University of Rwanda and the National Institute of Statistics of Rwanda (number: 0425/2014/10/NISR).

Provenance and peer review Not commissioned; externally peer reviewed.

Data sharing statement No additional data are available.

Open Access This is an Open Access article distributed in accordance with the Creative Commons Attribution Non Commercial (CC BY-NC 4.0) license, which permits others to distribute, remix, adapt, build upon this work noncommercially, and license their derivative works on different terms, provided the original work is properly cited and the use is non-commercial. See: http:// creativecommons.org/licenses/by-nc/4.0/

\section{REFERENCES}

1. WHO: Intimate partner and sexual violence against women: Factsheets. http://www.who.int/mediacentre/factsheets/fs239/en/. (accessed on 10 May 2016).

2. WHO: Understanding and addressing violence against women. http://www.who.int/reproductivehealth/topics/violence/vaw_series/en/. (accessed on 10 May 2016).

3. Shamu S, Zarowsky C, Roelens K, et al. High-frequency intimate partner violence during pregnancy, postnatal depression and suicida tendencies in Harare, Zimbabwe. Gen Hosp Psychiatry 2016;38:109-14.

4. Stockl H, Watts C, Kilonzo Mbwambo JK. Physical violence by a partner during pregnancy in Tanzania: prevalence and risk factors. Reprod Health Matters 2010;18:171-80.

5. Kita S, Haruna M, Matsuzaki M, et al. Associations between intimate partner violence (IPV) during pregnancy, mother-to-infant bonding failure, and postnatal depressive symptoms. Arch Womens Ment Health 2016;19:623-34.

6. Demelash H, Nigatu D, Gashaw K. A case-control study on intimate partner violence during pregnancy and low birth weight, southeast Ethiopia. Obstet Gynecol Int 2015;2015:394875.

7. Zakar R, Nasrullah M, Zakar MZ, et al. The association of intimate partner violence with unintended pregnancy and pregnancy loss in Pakistan. Int J Gynaecol Obstet 2016;133:26-31.

8. Idoko $P$, Ogbe $E$, Jallow $O$, et al. Burden of intimate partner violence in The Gambia: a cross sectional study of pregnant women. Reprod Health 2015;12:34.

9. Campbell JC. Health consequences of intimate partner violence. Lancet 2002;359:1331-6.

10. Asling-Monemi K, Naved RT, Persson LA. Violence against women and the risk of fetal and early childhood growth impairment: a cohort study in rural Bangladesh. Arch Dis Child 2009;94:775-9.

11. Lewis AJ, Austin E, Galbally M. Prenatal maternal mental health and fetal growth restriction: a systematic review. J Dev Orig Health Dis 2016;7:416-28.

12. Calkins K, Devaskar SU. Fetal origins of adult disease. Curr Prob/ Pediatr Adolesc Healthcare 2011;41:158-76.

13. Van Parys AS, Deschepper E, Michielsen K, et al. Intimate partner violence and psychosocial health, a cross-sectional study in a pregnant population. BMC Pregnancy Childbirth 2015;15:278.

14. Devries KM, Mak JY, Garcia-Moreno C, et al. Global health. The global prevalence of intimate partner violence against women. Science 2013:340:1527-8.

15. Small MJ, Gupta J, Frederic R, et al. Intimate partner and nonpartner violence against pregnant women in rural Haiti. Int J Gynaecol Obstet 2008;102:226-31.

16. Patel V, Abas M, Broadhead J, et al. Depression in developing countries: lessons from Zimbabwe. BMJ 2001;322:482-4.

17. Sipsma $\mathrm{H}$, Ofori-Atta A, Canavan M, et al. Empowerment and use of antenatal care among women in Ghana: a cross-sectional study. BMC Pregnancy Childbirth 2014;14:364.

18. Alhusen JL, Frohman N, Purcell G. Intimate partner violence and suicidal ideation in pregnant women. Arch Womens Ment Health 2015;18:573-8. 
19. Janssen PA, Holt VL, Sugg NK, et al. Intimate partner violence and adverse pregnancy outcomes: a population-based study. $A m$ J Obstet Gynecol 2003;188:1341-7.

20. National Institute of Statistics of Rwanda. Fouth Population and Housing Census. http://statistics.gov.rw/survey-period/ fourth-population-and-housing-census-2012 (Downloaded on 27 May 2016).

21. Rwanda Demographic and Health survey. 2005. https://dhsprogram. com/pubs/pdf/FR183/FR183.pdf. (Downloaded on 27 May 2016).

22. Rwanda Demographic and Health survey, 2010. https://dhsprogram. com/pubs/pdf/FR259/FR259.pdf. (Downloaded on 27 May 2016).

23. Masculinity and Gender based Violence in Rwanda. http://jliflc.com/ resources/masculinity-gender-based-violence-rwanda/. (Downloaded on 10 May 2016).

24. Organic Law Instituting the Penal Code of Rwanda. 2012. https:// www.ilo.org/dyn/natlex/docs/SERIAL/93714/109657/.../RWA-93714. pdf. (Downloaded on 2 June 2016).

25. Ntaganira J, Muula AS, Masaisa F, et al. Intimate partner violence among pregnant women in Rwanda. BMC Womens Health 2008;8:17.

26. Umubyeyi A, Mogren I, Ntaganira J, et al. Women are considerably more exposed to intimate partner violence than men in Rwanda: results from a population-based, cross-sectional study. BMC Womens Health 2014;14:99.

27. Tufton N, Patel RR. Prevalence of hypertensive disorders in a prenatal clinic in Zanzibar. Int J Gynaecol Obstet 2011;112:69-70.

28. Rurangirwa AA, Gaillard R, Steegers EA, et al. Hemodynamic adaptations in different trimesters among nulliparous and multiparous pregnant women; the Generation R study. Am $J$ Hypertens 2012;25:892-9.

29. World Health Organization. WHO Multi-country study on women's Health and Life Experiences, 2005. http://www.spc.int/hdp/index2. php?option=com_docman\&task=doc_view\&gid $=52 \&$ Itemid $=4$

30. Garcia-Moreno C, Jansen HA, Ellsberg M, et al. Prevalence of intimate partner violence: findings from the WHO multi-country study on women's health and domestic violence. Lancet 2006;368:1260-9.

31. Saddki N, Sulaiman Z, Ali SH, et al. Validity and reliability of the Malay version of WHO Women's Health and Life Experiences Questionnaire. J Interpers Violence 2013;28:2557-80.

32. Makayoto LA, Omolo J, Kamweya AM, et al. Prevalence and associated factors of intimate partner violence among pregnant women attending Kisumu District Hospital, Kenya. Matern Child Health J 2013;17:441-7.

33. Mahenge B, Likindikoki S, Stockl $\mathrm{H}$, et al. Intimate partner violence during pregnancy and associated mental health symptoms among pregnant women in Tanzania: a cross-sectional study. BJOG 2013;120:940-6.

34. Abebe Abate B, Admassu Wossen B, Tilahun Degfie T. Determinants of intimate partner violence during pregnancy among married women in Abay Chomen district, Western Ethiopia: a community based cross sectional study. BMC Womens Health 2016;16:16.

35. Mandal M, Hindin MJ. Men's controlling behaviors and women's experiences of physical violence in Malawi. Matern Child Health $J$ 2013;17:1332-8.

36. Balogun MO, Owoaje ET, Fawole OI. Intimate partner violence in southwestern Nigeria: are there rural-urban differences? Women Health 2012;52:627-45.
37. Jasinski JL. Pregnancy and domestic violence: a review of the literature. Trauma Violence Abuse 2004;5:47-64.

38. Kataoka Y, Imazeki M, Shinohara E. Survey of intimate partner violence before and during pregnancy among Japanese women. Jpn J Nurs Sci 2016;13:189-95.

39. Intimate partner violence among couples in $10 \mathrm{DHS}$ countries: predictions and health outcomes. https://dhsprogram.com/pubs/pdf/ AS18/AS18.pdf (Downloaded on 2 June 2016).

40. Mulawa M, Kajula LJ, Yamanis TJ, et al. Perpetration and victimization of intimate partner violence among young men and women in Dar es Salaam, Tanzania. J Interpers Violence 2016.

41. Omer K, Afi NJ, Baba MC, et al. Seeking evidence to support efforts to increase use of antenatal care: a cross-sectional study in two states of Nigeria. BMC Pregnancy Childbirth 2014;14:380.

42. Sabri B, Huerta J, Alexander KA, et al. Multiple intimate partner violence experiences: knowledge, access, utilization and barriers to utilization of resources by women of the African diaspora. $J$ Healthcare Poor Underserved 2015;26:1286-303.

43. Andersson N, Omer K, Caldwell D, et al. Male responsibility and maternal morbidity: a cross-sectional study in two Nigerian states. BMC Health Serv Res 2011;11(Suppl 2):S7.

44. Langston A, Weiss J, Landegger J, et al. Plausible role for $\mathrm{CHW}$ peer support groups in increasing care-seeking in an integrated community case management project in Rwanda: a mixed methods evaluation. Glob Health Sci Pract 2014;2:342-54.

45. Ministry of Health of Rwanda. National community health strategic plan. http://moh.gov.rw/fileadmin/templates/CHD_Docs/ CHD-Strategic_plan.pdf (Downloaded on 4 May 2016).

46. Mannell J, Jackson S, Umutoni A. Women's responses to intimate partner violence in Rwanda: rethinking agency in constrained social contexts. Glob Public Health 2016;11:65-81.

47. Farrokh-Eslamlou H, Oshnouei S, Haghighi N. Intimate partner violence during pregnancy in Urmia, Iran in 2012. J Forensic Leg Med 2014;24:28-32.

48. Semahegn A, Mengistie B. Domestic violence against women and associated factors in Ethiopia; systematic review. Reprod Health 2015;12:78.

49. James L, Brody D, Hamilton Z. Risk factors for domestic violence during pregnancy: a meta-analytic review. Violence Vict 2013;28:359-80.

50. Jackson CL, Ciciolla L, Crnic KA, et al. Intimate partner violence before and during pregnancy: related demographic and psychosocial factors and postpartum depressive symptoms among Mexican American women. J Interpers Violence 2015;30:659-79.

51. Deuba K, Mainali A, Alvesson HM, et al. Experience of intimate partner violence among young pregnant women in urban slums of Kathmandu Valley, Nepal: a qualitative study. BMC Womens Health 2016;16:11.

52. Jayasuriya $\mathrm{V}$, Wijewardena $\mathrm{K}$, Axemo $\mathrm{P}$. Intimate partner violence against women in the capital province of Sri Lanka: prevalence, risk factors, and help seeking. Violence Against Women 2011;17:1086-102.

53. WHO. World report on violence and health. http://www.who.int/ violence_injury_prevention/violence/world_report/en/summary_en. pdf.2002 (Downloaded on 14 June 2016).

54. Guest G, Bunce A, Johnson L, et al. Fear, hope and social desirability bias among women at high risk for HIV in West Africa. J Fam Plann Reprod Healthcare 2005;31:285-7. 